\title{
LA INCLUSIÓN EN EL SISTEMA FINANCIERO BOLIVIANO Y LAS MICROFINANZAS
}

Cristian Ricardo Nogales Carvajal y Carlos Alberto Foronda Rojas

\section{RESUMEN}

En el presente trabajo se analiza la evolución del grado de inclusión del sistema financiero boliviano en el periodo 2001-2009, empleando un panel de datos elaborado en base a información de la ASFI y FINRURAL. Se crea una medida sintética del desempeño financiero y otra del desempeño social para 56 instituciones financieras empleando Análisis Factorial, en base a un marco teórico por Beck, Morduch, Hamed y Flückiger. Se utiliza el indicador del desempeño social de las instituciones como una medida del grado de inclusión social que ha alcanzado el sistema. Se demuestra que el aumento del grado de inclusión del sistema ha tenido como actores principales a las instituciones financieras con mayor vocación social (microfinancieras no reguladas y reguladas por la ASFI), sin comprometer de manera alguna su desempeño financiero. Mediante un modelo de datos de panel se demuestra que un desempeño financiero sobresaliente por parte de estas instituciones es una de las principales causas del grado de grado de inclusión que tiene hoy el sistema financiero. El estudio concluye con algunas recomendaciones de política para mejorar aún más y de manera sostenible este nivel de grado de inclusión.

Palabras Clave: Microfinanzas, Análisis Factorial, Datos de Panel. 